\title{
Perfil dos visitantes do Parque Natural Municipal do Açude da Concórdia - Valença (RJ)
}

\section{Delfina Maria Soares Vaz}

\section{RESUMO}

O objetivo do presente trabalho foi traçar o perfil dos visitantes do Parque Natural Municipal do Açude da Concórdia, em Valença (RJ). A pesquisa consistiu na aplicação de 70 questionários no período de fevereiro a maio de 2008 aos visitantes do Parque de Valença. Os resultados obtidos foram eficazes para conhecer as características estruturais dos visitantes, suas motivações, suas expectativas, suas demandas para direcionar as atividades de manejo, atender as necessidades de lazer e promover melhorias nos serviços oferecidos. Fez-se um paralelo dos resultados obtidos com trabalho semelhante efetuado no Parque Natural Municipal do Mendanha, no Bairro de Bangu, no município do Rio de Janeiro. Constatou-se que a motivação que mais estimula as pessoas a visitarem esses parques é apreciar a natureza. $O$ trabalho mostrou que as preferências e padrões de comportamento dos visitantes são influenciados por características sociais, econômicas e culturais dos visitantes. Com os resultados obtidos pretende-se oferecer à Administração do Parque subsídios para a elaboração do seu Plano de Manejo e a viabilização das expectativas dos visitantes.

PALAVRAS-CHAVE: Unidade de Conservação, Ecoturismo, Percepção Ambiental.

\section{Profile of Concordia Reservoir City Natural Park Visitors - Valença - RJ, Brazil}

\section{ABSTRACT}

The aim of this study was to establish the profile of visitors to the Concórdia Reservoir Natural Municipal Park, in the city of Valença (RJ). The research consisted in the application of 70 questionnaires, from February to May 2008, to visitors to the park. The results were effective to meet the structural characteristics of visitors, their motivations, their experiences, their expectations and demands for direct management activities, meet the needs of leisure and promote improvements in services offered. It has a comparison of results with similar work done in the Mendanha Municipal Natural Park in the Bairro de Bangu, Rio de Janeiro county - RJ. It was found out that the motivation that encourages more people to visit these parks is to enjoy the nature. The study showed that the preferences and behavior patterns of visitors are influenced by social, economic and cultural views. With the results obtained intends to offer to the Park Service grants to the preparation of its Management Plan and the viability of the expectations of visitors.

KEYWORDS: Protected Areas, Ecotourism, Environmental Perception. 


\section{1- Introdução}

A procura por áreas verdes, parques naturais e mesmo áreas arborizadas é cada vez maior, pois conciliam-se o bem estar e descanso com a sensação de prazer através do contato com a natureza, consequentemente essas áreas são cada vez mais valorizadas, principalmente se aliadas com lazer.

Muitos lugares que apresentam parques estaduais e nacionais são alvo de atração de turistas, que crescem constantemente.

Como uma forma de conhecer este público frequentador, vários trabalhos são realizados para esta finalidade. O resultado dos levantamentos é que vai subsidiar os projetos futuros das áreas naturais, a partir da compreensão dos visitantes. Os visitantes de Unidades de Conservação podem ser valiosos para a administração destas áreas, tanto para apoiar os seus esforços para a conservação, como indiretamente pelo aumento de renda na manutenção das áreas naturais e das populações locais, diminuindo a pressão sobre recursos naturais.

O turismo em Unidades de Conservação, se regulamentado e controlado adequadamente, oferece um dos usos econômicos menos prejudiciais destas áreas. Especialmente o ecoturismo pode ser uma ferramenta poderosa para assegurar a verdadeira proteção destas áreas.

Várias Unidades de Conservação trabalham com os resultados de pesquisas para fazer modificações ou mesmo para implantar o Plano de Manejo. Como as atividades recreativas tornam-se pontos de atração à visitação, também trazem a vantagem de geração de renda, como forma de ajudar na manutenção dos parques. Os visitantes das áreas naturais sentem a necessidade de experimentar sensações diferentes do dia-a-dia, principalmente quando buscam o contato com a natureza para o seu bem estar. Portanto, eles mesmos, podem ser valiosos para apoiar os esforços da administração destas áreas como na colaboração de sugestões.

\section{2 - Objetivos}

O presente trabalho buscou analisar o perfil dos visitantes do Parque Natural Municipal do Açude da Concórdia, em Valença (RJ). Como objetivo específico foi analisar as características socioculturais, motivacionais, oportunidades vivenciadas e grau de satisfação dos visitantes do Parque Natural Municipal do Açude da Concórdia.

\section{3 - Material e Método}

\section{1 - Área de estudo}

De acordo com Ribeiro (1999), o Parque Natural Municipal do Açude da Concórdia está localizado no município de Valença (RJ), na Serra da Concórdia, entre os vales do Rio Preto e do Paraíba do Sul. A Serra da Concórdia está inseri- 
da na Reserva da Biosfera da Mata Atlântica (UNESCO/IEF) e no Corredor Ecológico da Serra do Mar - SP/RJ. Suas coordenadas UTM são $X=7.528 .000$ ao norte e $Y=627.300 .000$ a leste, sua sede tem como waypoint $S 22^{\circ} 20^{\prime} 885^{\prime \prime}$ e W $43^{\circ}$ 45'756". Possui aproximadamente 23 ha (hectares) e está 760 metros acima do nível do mar.

É uma área protegida por lei e encontra-se inserida na categoria de manejo de proteção integral do Sistema Nacional de Unidades de Conservação.

$\mathrm{O}$ açude, com águas límpidas e transparentes, tem profundidade máxima de 14 metros e mínima de 6 metros, seu contorno é irregular com cerca de 4,2 Km. O acesso se dá pela BR 116 em seguida a RJ 145 até a localidade de Vira-Tábua, daí por $5 \mathrm{Km}$ de estradas vicinais até sua entrada principal.

De acordo com o Projeto de Criação, Implantação e Gestão da Primeira Unidade de Conservação do Município de Valença (RIBEIRO, 1999) referência de onde foram tiradas as informações, são objetivos do Parque Natural Municipal do Açude da Concórdia:

- $\quad$ proteger e preservar os remanescentes da Mata Atlântica;

- $\quad$ preservar os exemplares raros, endêmicos e ameaçados de extinção ou insuficientemente conhecidos da fauna e da flora;

- integrar corredores ecológicos capazes de garantir a preservação da diversidade biológica da região;

- $\quad$ proporcionar o desenvolvimento de iniciativas que conciliem viabilidade econômica da região com utilização racional dos recursos naturais;

- $\quad$ estimular as atividades de recreação, Educação Ambiental e pesquisa científica quando compatíveis com os demais objetivos do Parque;

- $\quad$ proteger os recursos hídricos do município.

$\bullet$

O Parque tem funcionamento diário com portaria, sede administrativa, abrigo para pesquisadores, banheiros públicos, churrasqueiras, área de camping e trilhas interpretativas. Também possui aluguel de barcos e caiaques. Não é permitido banhar-se ou pescar no açude.

O Parque atende a turistas que vão visitar a região para apreciar a natureza, relaxar, fazer trilhas, acampar, utilizar os quiosques disponíveis no local e praticar atividades de recreação, e também atende a alunos dos cursos de graduação e pós-graduação oferecidos na região. É mister informar que estes visitantes buscam o local particularmente em número reduzido, com maior frequência nos períodos de abril a setembro, que é o período de menor índice pluviométrico. A maioria dos alunos do ensino fundamental ou médio, quando visitam o Parque, o faz junto com seus familiares. 


\section{2 - Histórico da Área}

Segundo Ribeiro (1999), o açude da Concórdia foi construído por volta de 1890, nos tempos do Barão de Santa Mônica, na fazenda do mesmo nome.

Em 1929 o engenheiro militar Sr. José Vicente de Araújo e Silva apresenta minucioso estudo de abastecimento de água, acompanhado de projetos das novas instalações, que viriam dotar a cidade de Valença. O açude é estudado, realiza-se analise de suas águas e constata sua potabilidade e sua boa vazão.

Em 11/12/1930 o governo do estado do Rio desapropria a área do açude e cede ao Município de Valença, que o mantém e o administra desde então.

Em 1950 a população passa a consumir toda a água do açude que torna-se insuficiente no final dos ano 60, devido a má captação, por ocasião das secas.

Em 1990, com a promulgação da Lei Orgânica do Município o Açude da Concórdia passa a ser reconhecido oficialmente como Área de Preservação Permanente APP.

Em 1992 várias tentativas são feitas por parte da organização não governamental local, como a Associação de Defesa do Meio Ambiente do Médio Paraíba AMA Médio Paraíba, de sensibilizar as autoridades dos governos municipal e estadual da importância de ser criar uma Unidade de Conservação da natureza na área do açude. A partir de 2000 estudos preliminares são efetuados em parceria com o Instituto Estadual de Florestas do Rio de Janeiro que demonstra a viabilidade técnica da proposta.

Através do Decreto Municipal 65, de 12 de setembro de 2001 é criado o Parque Natural Municipal do Açude da Concórdia, ficando a cargo da Ong AMA Médio Paraíba a responsabilidade pela a sua administração.

\section{3 - Método}

Um estudo do perfil sócio econômico cultural dos visitantes do parque, além de suas expectativas, só é possível através da aplicação de questionários que possam levantar esses dados para tomadas de decisões.

Para a elaboração dos questionários procuraram-se referências bibliográficas dos seguintes trabalhos: Tomiazzi e VIllarinho (2005) e Castro et al. (2007).

Como resultado, para atender aos objetivos, foram elaborados dois tipos de questionários:

$1^{\circ}$ - levantamento de informações sócio, econômico e cultural dos visitantes e a motivação dos mesmos para irem visitar. Entregue na entrada do Parque.

$2^{\circ}$ - experiências vivenciadas durante a visitação, expectativas futuras e grau de satisfação. A ser entregue na saída do Parque .

Os questionários foram aplicados no período de fevereiro a junho de 2008. Contou-se com a colaboração dos funcionários do Parque para entrega de alguns 
questionários e outros foram através de entrevistas. Como resultado final, participaram 70 visitantes, não participando os menores de 15 anos.

De posse dos questionários respondidos, os dados foram analisados quantitativamente, através de porcentagens e colocados em quadros e gráficos.

Os resultados obtidos são comparados com o trabalho de Tomiazzi e VIllarinho (2005) efetuado no período de abril de 2004 a janeiro de 2005 no Parque Natural Municipal do Mendanha, no bairro de Bangu no município do Rio de Janeiro (RJ), com amostra de 407 entrevistados.

\section{Resultados e Discussão}

No quadro abaixo buscou-se conhecer a faixa etária dos visitantes que frequentam o parque, para entendermos melhor as suas necessidades.

Quadro 1 - Faixa etária dos entrevistados

\begin{tabular}{|l|l|}
\hline Visitantes \% & Respostas \\
\hline $13,3 \%$ & 10 a 20 anos \\
$9,8 \%$ & 21 a 30 anos \\
$14,7 \%$ & 31 a 40 anos \\
$11,2 \%$ & 41 a 50 anos \\
$7,0 \%$ & + de 50 anos \\
\hline
\end{tabular}

Observou-se, no quadro acima, que os visitantes de 31 a 40 e 41 a 50 anos, juntos, correspondem a $25,9 \%$ dos entrevistados. Nota-se que por estarem dentro da faixa economicamente ativa, tais usuários preferem afastar-se do ritmo das cidades, na procura por lazer em áreas naturais, o que sugere a busca por qualidade de vida. Acredita-se que a faixa de 10 a 20 anos, com a porcentagem de $13,3 \%$, possa representar os filhos que acompanham os pais, e também grupos de jovens que buscam um lazer alternativo. Já a pouca procura pela faixa etária de 21 a 30 anos, deve-se a necessidade de mais opções de lazer urbano.

Já o interesse dos visitantes acima de 50 anos, que representam $7 \%$, pode insinuar a necessidade de contato direto com a natureza.

No trabalho efetuado no Parque do Mendanha, no bairro do Bangu, município do Rio de Janeiro (RJ), a faixa etária predominante foi acima dos 40 anos correspondendo a $42 \%$ dos entrevistados. As faixas etárias entre 21 a 30 e 31 a 40 anos, características da população economicamente ativa, apresentaram o mesmo percentual de $21 \%$ cada faixa, o que demonstra que as opções de lazer em áreas verdes urbanas públicas atendem suas expectativas. Observa-se, porém, que apesar de o Par- 
que do Mendanha estar melhor localizado, dentro de área urbana, e dispor de opções de recreação, o público jovem entre 11 e 21 anos, que correspondem a $16 \%$ da pesquisa, é o que menos frequenta, preferindo outras atividades de recreação e lazer.

No quadro 2, levantou-se o nível de escolaridade dos visitantes.

Quadro 2 - Escolaridade dos Entrevistados

\begin{tabular}{|l|l|}
\hline Visitantes \% & Resultados \\
\hline $4,9 \%$ & Fundamental completo \\
$5,6 \%$ & Fundamental incompleto \\
$6,3 \%$ & Médio completo \\
$4,2 \%$ & Médio incompleto \\
$7,0 \%$ & Graduação completo \\
$7,0 \%$ & Graduação incompleto \\
10,5 & Pós-grad completa \\
$5,6 \%$ & Pós-grad incompleta \\
\hline
\end{tabular}

Observa-se no quadro 2 acima, que a escolaridade dos visitantes do parque é alta, por ele ser visitado por estudantes de curso superior da região.

Nota-se pelos percentuais de $7 \%$ para os entrevistados com graduação completa e incompleta, que representam as visitas técnicas dos cursos e o retorno após o término destes. O mesmo acontece com os entrevistados com nível de pósgraduação. A porcentagem total da escolaridade superior foi de $30 \%$, que pode coincidir com a faixa etária que mais frequentam o parque de 31 a 40 anos. Como o acesso é dificultado pela estrada, a visitação fica restrita a classe de pessoas que possui veículo próprio e praticamente não recebe visitas escolares . resultado foi diferente no trabalho do Parque do Mendanha em que a escolaridade mais expressiva foi de ensino médio, correspondente a $47 \%$ dos entrevistados. A porcentagem total da escolaridade superior foi de $24 \%$, acima do percentual da população com nível superior na região (10\%). Uma explicação para o fato é que o Parque do Mendanha apesar de estar situado na área urbana do município, o bairro situa-se no subúrbio da cidade e concentra pessoas com menor escolaridade e que buscam na proximidade de onde moram o lazer mais acessível.

No quadro 3 abaixo, foi levantado a atividade que os visitantes exercem. Observa-se que a maioria estuda e trabalha, correspondendo a faixa etária da população ativa e complementando o resultado da questão anterior, onde os usuários fazem parte do grupo de estudantes de graduação e pós-graduação em grande parte. Na resposta referente à não estudar e não trabalhar acredita-se estar incluídos os apo- 
sentados.

O resultado deste item no diagnóstico do Parque do Mendanha, foi que a maioria é composta por trabalhadores formais e informais, com percentual de $52 \%$, não foi abordada a atividade relativa ao estudo, mas evidencia-se pelos resultados anteriores que os visitantes só trabalham. O percentual de aposentados é de $20 \%$, superior ao de estudantes e dona-de-casa ambos com 14\%. Talvez demonstre a ligação entre disponibilidade de tempo e a intensidade em ocupações recreativas.

Evidencia-se a relação entre a atividade exercida com a faixa etária dos usuários que mais se utilizam do Parque.

Quadro 3 - Atividade exercida pelos entrevistados

\begin{tabular}{|c|l|}
\hline Visitantes \% & Respostas \\
\hline $16,1 \%$ & Só trabalha \\
$9,8 \%$ & Só estuda \\
$20,3 \%$ & Estuda e trabalha \\
$1,4 \%$ & Não estuda, não traba- \\
& lha \\
2,8 & Cuida do lar \\
& \\
\hline
\end{tabular}

No quadro abaixo (4) se verificou que a maior porcentagem de visitantes é do sexo feminino, sugerindo a crescente preocupação com a qualidade de vida, atividades físicas e de lazer. Também confirmado no trabalho do Parque do Mendanha a porcentagem de $55 \%$ para o sexo feminino.

Quadro 4 - Gênero dos entrevistados

\begin{tabular}{|l|l|}
\hline Visitantes \% & Respostas \\
\hline $52,8 \%$ & Feminino \\
$47,14 \%$ & Masculino \\
\hline
\end{tabular}

No próximo quadro (5) analisamos o nível salarial dos visitantes, em termos de salários mínimos (SM). 
Quadro 5 - Nível salarial dos entrevistados

\begin{tabular}{|l|l|}
\hline Visitantes \% & Respostas \\
\hline $23,1 \%$ & 1 a 3 SM \\
$17,5 \%$ & 4 a 6 SM \\
$1,4 \%$ & 7 a 8 SM \\
$1,4 \%$ & 9 a 10 SM \\
\hline
\end{tabular}

Observando o quadro 5 acima verificamos que a maior parte dos entrevistados estão na faixa salarial de 1 a 6 salários mínimos, correspondendo a 40,6\%, apesar da alta escolaridade. O que conclui o baixo padrão de remuneração da região.. Observase que as menores porcentagens $1,4 \%$ estão para rendimento entre 7 a 10 salários mínimos, possivelmente representam profissionais com estabilidade financeira, portanto dentro da faixa etária já analisada anteriormente. Destaca-se ainda, os entrevistados com renda acima de 10 salários mínimos que optam por visitação em Unidades de Conservação. Este item não constou no questionário realizado no Parque do Mendanha foi mencionado em material e método sobre a área de estudo, que a renda média da região e de cerca de 4 salários mínimos.

Observa-se no quadro 6 abaixo que o fator de apreciar a natureza é a maior motivação dos visitantes do parque. A seguir vem relaxar, o que demonstra a busca por descanso em área natural. $O$ interesse de fazer trilhas ser maior que as atividades de recreação, sugere-se um maior interesse ambiental pela área visitada.. Também confirmamos que a porcentagem de estudo é bem expressiva, devido as visitas técnicas de estudantes de faculdade. A utilização de churrasqueiras e quiosques foram percentualmente iguais com a recreação, onde conclui-se que grupos de amigos ou familiares que permanecem no parque durante todo dia, desfrutando das atividades de lazer oferecidas. No levantamento do Parque do Mendanha dentre os motivos que atraem os visitantes é o clima agradável do local, devido o subúrbio do Bangu possuir as maiores temperaturas da região. Confirma-se ali a atração pela natureza como maior motivação de visitação correspondendo a $40 \%$ dos entrevistados, seguido da piscina $31 \%$, devido a grande distância das praias. As trilhas também são consideradas como terceira opção de preferência. Devido à diversidade de opções de lazer que o parque oferece a presença marcante de visitantes do próprio local evidencia a popularidade e a sua importância na região. Também ocorre elevada visitação de grupos, coordenados por profissionais, como de turismo ecológico, de Educação Ambiental, de escolas, de terceira idade e esportivos, motivados pelos atrativos naturais do Parque. A frequência de visitação por moradores do próprio local é bem alta, pois além do parque oferecer opções de lazer e recreação, ocorre fornecimento de serviços ambientais associados às questões relativas à melhoria de qualidade de vida regional. A gratuidade e a segurança também são fatores motivacionais, devido a elevados índices de criminalidade na região. 
Quadro 6 - Motivações que atraem os visitantes do Parque

\begin{tabular}{|l|l|}
\hline Visitantes \% & Resultados \\
\hline $28 \%$ & Apreciar a natureza \\
$18 \%$ & Relaxar \\
$14 \%$ & Fazer trilhas \\
$12,6 \%$ & Acampar \\
$11,9 \%$ & Estudo \\
$6,3 \%$ & Usar quiosque e churrasqueiras \\
$6,3 \%$ & Recreação \\
\hline
\end{tabular}

A seguir no quadro 7 serão observadas as experiências vivenciadas pelos visitantes durante a permanência no Parque.

Quadro 7 - Experiências vivenciadas dos visitantes

\begin{tabular}{|l|lllll|}
\hline & \multicolumn{5}{|c|}{ Situação Atual (\%) * } \\
\hline Oportunidades experienciadas & 1 & 2 & 3 & 4 & 5 \\
\hline Tratar a natureza com respeito & $0 \%$ & $0,7 \%$ & $6,3 \%$ & $12,6 \%$ & $25,8 \%$ \\
Experimentar paz, tranquilidade & $0 \%$ & $1,4 \%$ & $11,9 \%$ & $14,0 \%$ & $16,8 \%$ \\
Sentir-se livre & $0,7 \%$ & $2,1 \%$ & $9,8 \%$ & $17,5 \%$ & $15,4 \%$ \\
Não ter a sensação das horas & $2,1 \%$ & $1,4 \%$ & $11,9 \%$ & $12,6 \%$ & $15,4 \%$ \\
Confraternizar-se com amigos & $2,1 \%$ & $1,4 \%$ & $11,2 \%$ & $16,8 \%$ & $14,0 \%$ \\
Exercitar-se & $2,8 \%$ & $4,9 \%$ & $11,9 \%$ & $16.8 \%$ & $8,4 \%$ \\
Aventurar-se & $2,1 \%$ & $7,0 \%$ & $18,9 \%$ & $9,8 \%$ & $7,0 \%$ \\
Recreação & $2,1 \%$ & $9,8 \%$ & $16,1 \%$ & $10,5 \%$ & $6,3 \%$ \\
\hline
\end{tabular}
*Opções: ( 1 ) nenhuma
(2) baixa
(3)média
(4)alta
(5) muito alta

No quadro 7 acima observa que as experiências vivenciadas coincidem com a motivação dos visitantes de contato com a natureza juntamente com a de relaxar. Observa-se a necessidade de desligar-se do dia-a-dia, da sensação de liberdade e de não ter noção das horas. A busca por atividades físicas e recreação fica em segundo plano. Observa-se a relação das oportunidades vivenciadas com a escolaridade (superior), a faixa etária (31 a 40 anos) e com as atividades exercidas dos visitantes. Os padrões de comportamento diferem devido ao perfil sócio, econômico e social, 
conforme observado nos quadros anteriores.

No diagnóstico realizado no Parque de Mendanha, foi questionado sobre a atividade principal dos entrevistados durante a sua permanência no local, onde destacou-se a prática de caminhadas com $55 \%$ da preferência, que podemos relacionar com a faixa etária mais predominante acima de 40 anos. Como segunda atividade mais escolhida foi de nadar (26\%), visto que o local possui piscinas, o bairro apresenta temperaturas elevadas e situa-se distante das praias. Observa-se que as atividades escolhidas estão mais adequadas com as características dos visitantes do parque, que buscam o lazer mais acessível ao padrão de vida do local.

No quadro 8 abaixo, serão analisadas as expectativas futuras dos visitantes:

Quadro 8 - Expectativas futuras dos visitantes do Parque

\begin{tabular}{|l|l|}
\hline Visitantes \% Expectativas dos Visitantes & Respostas \\
\hline Oferecer esportes radicais & $26,6 \%$ \\
Disponibilizar guias para trilhas & $22,4 \%$ \\
Oferecer mais barcos e caiaques & $21,0 \%$ \\
Mais trilhas & $19,6 \%$ \\
Oferecer venda de alimentos & $13,3 \%$ \\
Aumento da área de camping & $12,6 \%$ \\
Oferecer mais quiosques e churrasquei- & $12,6 \%$ \\
\hline
\end{tabular}

Os resultados do quadro 8 acima apontam a necessidade no incremento de atividades de lazer, como esportes radicais relacionados com a natureza, cuja procura para estas atividades é cada vez mais frequente em ambientes naturais. A presença de guias para trilhas demonstrou a precisão de maior conhecimento sobre a área visitada. Oferecer mais barcos e caiaques também indica a preferência para um lazer alternativo, principalmente em contato com a água, pois a região não possui rio para a prática de esportes aquáticos e porque está também distante de praias. Observouse menor interesse em ampliar as áreas de camping e a quantidade de churrasqueiras. Como o Parque não oferece venda de alimentos, alguns visitantes sentiram esta carência. Não houve expectativas referentes a cursos e palestras com temas ambientais, em função da bagagem cultural dos estudantes de curso superior e também devido o Parque não ser visitado por estudantes de ensino fundamental e médio. Em outras expectativas que não constava no questionário somente $1,4 \%$ sugeriram o trabalho de Educação Ambiental. Já no Parque do Mendanha a sugestão mais significativa foi a implantação de cursos e palestras com temas ambientais com $33 \%$ das respostas, seguida da abertura de novas trilhas, com 30\%. A distribuição de folhetos informativos e a instalação de novos equipamentos de recreação obtiveram $13 \%$ das respostas em ambos. No item outros (11\%) foram incluídas as demais sugestões, 
que não constavam no questionário, como: aumento do trabalho junto as escolas, identificação das espécies, interpretação das trilhas ecológicas, instalação de equipamento de ginástica, cobrança de taxa de visitação e a liberação da utilização de aparelhos sonoros. Estas respostas demonstram a necessidade dos visitantes de obter mais conhecimento sobre a área ambiental.

O grau de satisfação dos usuários que frequentam o Parque Natural Municipal do Açude da Concórdia pode ser verificado no quadro 9 abaixo, superando as expectativas dos visitantes, devido a sua boa infra-estrutura, sinalizações e atrativos naturais, apesar do Parque não ter assiduidades de frequências. O grau de satisfação também percebido no Parque Natural Municipal do Mendanha, pela sua acessibilidade, segurança e a gratuidade atendendo a boa parte da população que frequentam de 1 a 3 vezes por ano $(81 \%)$.

No quadro 9 abaixo analisamos o grau de satisfação dos visitantes.

Quadro 9 - Grau de satisfação dos visitantes

\begin{tabular}{|l|l|}
\hline Visitantes \% & Respostas \\
\hline $34 \%$ & Superou as expectativas \\
$27 \%$ & Atendeu as expectativas \\
$14 \%$ & Razoável \\
$0 \%$ & Ruim \\
\hline
\end{tabular}

\section{Conclusão}

O levantamento dos resultados obtidos foi eficiente para traçar o perfil dos visitantes do Parque Natural Municipal do Açude da Concórdia, além de permitir o conhecimento de suas motivações e expectativas. Embora ambos os parques satisfaçam os visitantes, os mesmos sugerem implantações de alternativas de recreação.

Como o Parque Natural Municipal do Açude da Concórdia possui pouco tempo de existência para visitações e pouca divulgação, o fluxo de usuários ainda é pequeno e diminui bastante quando o acesso torna-se prejudicado pelas chuvas. Devido a isto a maior parte da população da região desconhece o local.

Conclui-se que fatores como idade, escolaridade, nível salarial e atividade dos visitantes ditam as necessidades, as preferências e o comportamento dos visitantes como também influência nas motivações, experiências vivenciadas e principalmente nas expectativas futuras.

Os dados obtidos neste trabalho permitem uma maior compreensão da vital importância do Parque para o município, tanto como potencial turístico, como para estudo de campo. Sugere-se que a Secretaria de Educação promova: 
- $\quad$ capacitação dos professores de ciências na área de Unidades de Conservação;

- $\quad$ organização de visitações programadas de escolas com guias para trilhas;

- $\quad$ palestras nas escolas, com apresentação de slides, sobre o Parque e sua importância para a região;

- $\quad$ trabalhos referentes ao Parque, principalmente por ocasião de datas alusivas ao meio ambiente;

- $\quad$ trabalhos de Educação Ambiental com o envolvimento da comunidade.

Deve ser feita a distribuição de folhetos informativos sobre o Parque para serem entregues aos turistas visitantes que tiverem interesse em conhecer mais sobre as características do local. Importante se faz também a divulgação junto à rede hoteleira para a formação de grupos de turistas visitantes, com a presença de guias capacitados que possam desenvolver uma consciência ambiental de conservação atrelada ao conhecimento sobre a natureza do parque.

É preciso divulgar, valorizar e preservar o patrimônio natural para agora e para as futuras gerações.

\section{Referências Bibliográficas}

RIBEIRO, L.F. Implantação do Parque Natural Municipal do Açude da Concórdia, Valença, Rio de Janeiro. Monografia, Curso de Pós-Graduação em Administração e Manejo de Unidades de Conservação - AMUC, Valença, 1999. Disponível em http:// www.amamedioparaiba.xpg.com.br/mono.doc, acessado em 16-out-2009.

CASTRO, J.F.; FARIA, H.H.; PIRES, A.S.; OLIVIER, S.D. O Perfil dos Visitantes do Parque Estadual do Morro do Diabo, Estado de São Paulo. In: Congresso Nacional de Ecoturismo, 2007, Itatiaia, Anais ... Itatiaia, out. 2007, p.113-116.

TOMIAZI, A.B.; VILLARINHO, F.M. Perfil dos Visitantes do Parque Natural Municipal do Mendanha, Município do Rio de Janeiro (RJ).2005. Tese (Pós-Graduação em Ciências Florestais), Universidade Federal de Lavras, Lavras.

Delfina Maria Soares Vaz: Pós Graduada em Gestão e Auditoria Ambiental pela Universidade Gama Filho

Email: delfinavaz@hotmail.com

Data de submissão: 29 de outubro de 2009.

Data do aceite: 12 de dezembro de 2009. 